\title{
Intellectual property, technology transfer and manufacture of low-cost HPV vaccines in India
}

\author{
Swathi Padmanabhan, Tahir Amin, Bhaven Sampat, Robert Cook-Deegan \& Subhashini Chandrasekharan \\ An empirical study of the impact of patenting and licensing on regional manufacturing of human papilloma virus \\ vaccines to help improve vaccine affordability and access.
}

C ervical cancer, the leading cause of female cancer mortality worldwide, disproportionately affects women in low- and middleincome countries (LMCs). Four-fifths of the nearly 275,000 annual cervical cancer-related deaths occur in LMCs where routine gynecological screening is minimal or absent ${ }^{1,2}$. Two new prophylactic vaccines, Gardasil from Merck (Whitehouse Station, New Jersey, USA) and Cervarix from GlaxoSmithKline (GSK; London) have proven effective in preventing human papilloma virus (HPV)induced cervical lesions and some sequelae. Both vaccines are composed of HPV-L1 major capsid antigen virus-like particles (VLPs), and both prevent persistent infection from HPV-16 and HPV-18, which cause nearly $70 \%$ of cervical cancers ${ }^{3}$. Gardasil also contains L1 antigens from HPV strains 6 and 11 , which are associated with genital warts. Costing at least $\$ 300$ for the three-dose regimen, Gardasil is one of the most expensive vaccines introduced so far $^{4}$. Its private market price exceeds $\$ 500$ in several developed and developing countries ${ }^{5}$, which few can afford in most LMCs ${ }^{1,6,7}$.

Price discrimination by pharmaceutical companies could improve vaccine access in LMCs. Merck introduced Gardasil in India at about $\$ 171$ for the three-dose regimen ${ }^{8}$. Although

Swathi Padmanabhan, Robert Cook-Deegan and Subhashini Chandrasekharan are at the Center for Genome Ethics, Law \& Policy, Institute for Genome Sciences \& Policy, Duke University, Durham, North Carolina, USA; Tahir Amin is at the Initiative for Medicines Access and Knowledge, New York, New York, USA; and Bhaven Sampat is at the Mailman School of Public Health, Columbia University, New York, New York, USA.

e-mail: shubha.c@duke.edu such pricing enables middle-class access in some emerging economies, the vaccine remains unaffordable for most low- and middle-income populations in LMCs. Prices must fall below $\$ 2$ per dose to make broad access possible in low-income populations, especially in countries where gross domestic product per capita is below $\$ 1,000$ (refs. 9,10). It is unlikely that Merck or GSK can reduce vaccine prices to match these affordability targets because of the high production costs associated with their vaccines ${ }^{11}$. Company donations can also improve access $^{12,13}$. Merck donated about 130,000 doses to PATH for demonstration studies in India, Peru and Vietnam ${ }^{14}$. Through the Gardasil Access Program, Merck aims to extend its support to LMCs and has pledged to make 3 million doses of vaccine available to eligible countries ${ }^{15}$. However, reliance on pharmaceutical company donations alone is unsustainable. Alternatively, donor-aided vaccine purchase can significantly increase vaccine access by facilitating distribution of highly discounted vaccines in eligible LMCs $^{16}$. The Global Alliance for Vaccines and Immunization (GAVI) recently prioritized $\mathrm{HPV}$ vaccines ${ }^{17}$. However, owing to a $\$ 4$ billion deficit and existing financial commitments to other vaccines, it might be unable to finance HPV vaccines ${ }^{18}$. Donors often face tradeoffs, and high prices limit the quantities of vaccines or treatments they can subsidize ${ }^{19}$.

Vaccine manufacturing in LMCs can also reduce prices. Over the past decade, manufacturers in India, Cuba, China and Brazil have demonstrated their capacity to produce lowcost vaccines that meet international quality standards. They primarily serve low-income markets, supplying $64 \%$ of childhood vaccines procured by UNICEF and $43 \%$ of vaccines procured by GAVI ${ }^{20,21}$. Recombinant hepatitis $\mathrm{B}$ (HBV) vaccines illustrate the potential impact of such manufacturers in improving vaccine access in LMCs. When introduced in the early 1980 s, the HBV vaccine was priced at $\$ 50-80$ per dose, one of the most expensive prophylactic vaccines at that time $e^{21}$. However, developing country vaccine manufacturers (DCVMs), using alternate expression platforms suitable for low-cost development, successfully brought inexpensive $\mathrm{HBV}$ vaccines to market in the 1990s. The ensuing competition reduced market prices to less than $\$ 0.30$ per dose $\mathrm{p}^{21,22}$. Procurement costs for large vaccination programs consequently decreased, allowing wider access to the vaccine in $\mathrm{LMCs}^{21}$. DCVMs are therefore potentially important suppliers of low-cost HPV vaccines.

For successful production, DCVMs require access to relevant technology, which can be protected by intellectual property (IP) rights. Although DCVMs have faced few patent barriers so far, changes adopted by developing countries to comply with the World Trade Organization's Agreement on Trade Related Aspects of Intellectual Property Rights might create new obstacles for vaccine development ${ }^{23}$. Before the agreement, many LMCs did not award product patents for biopharmaceuticals, including vaccines. Now, however, DCVMs must consider international pharmaceutical companies' product patent rights on vaccines and related technologies. Patents granted in developing countries might constrain the ability of manufacturers to develop vaccines and/or to sell vaccines in local and international LMC markets (Fig. 1), thereby reducing their development incentives.

Two recent reports have suggested that IP might be a barrier for DCVMs who are interested in developing HPV vaccines ${ }^{24,25}$. However, publicly available information about the patenting and licensing of HPV vaccine technologies in developing countries is minimal. 


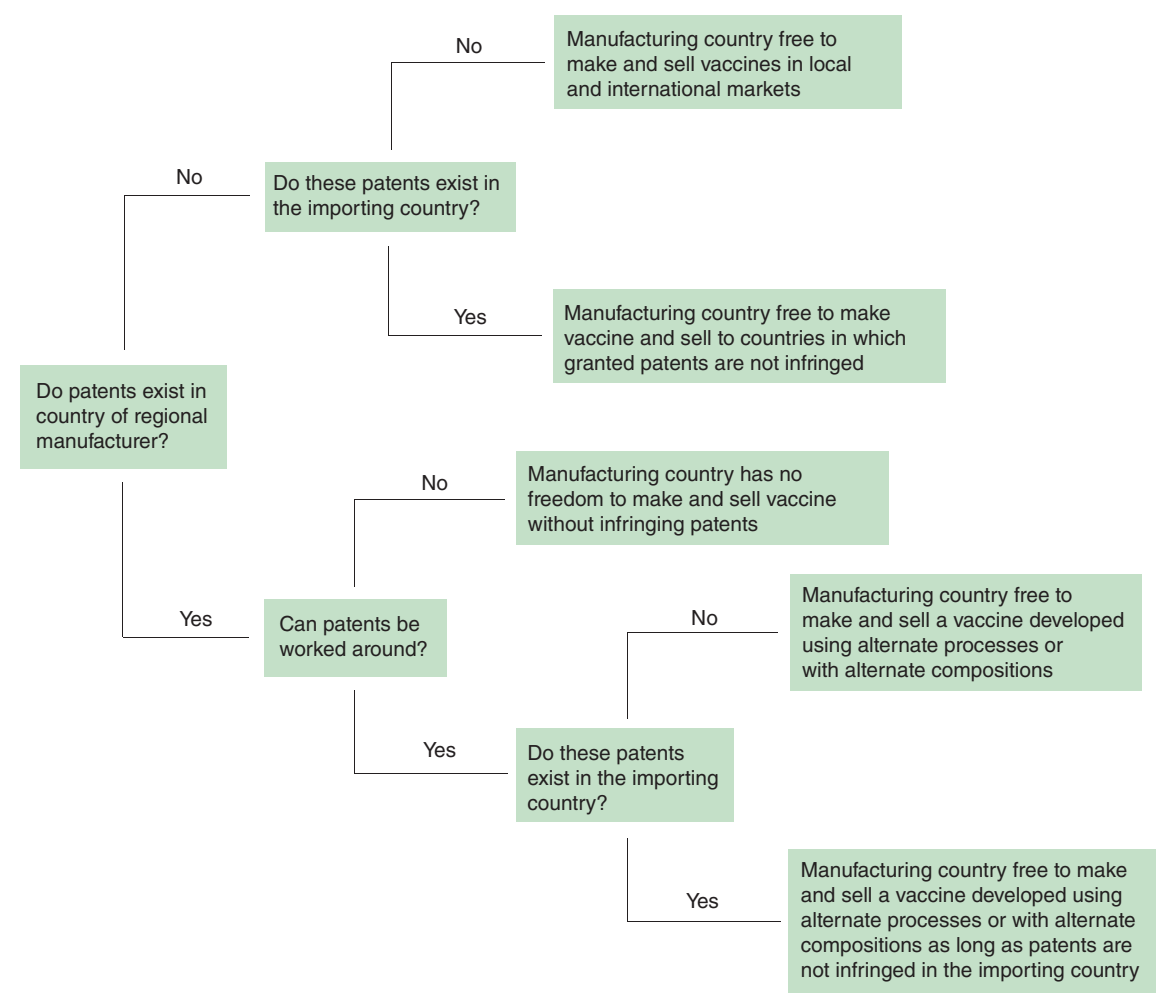

Figure 1 Impact of patents on manufacturing, sale, and/or export of 'bio-similar' HPV vaccines by developing country vaccine manufacturers. Patents existing in the country of the manufacturer that claim the 'composition of matter' of necessary antigens (e.g., nucleic acid and/or amino acid sequences of the L1 proteins) or the vaccine itself (e.g., VLPs made of L1 antigens) would prevent DCVMs from developing and selling vaccines in their country without a license from the patent owner. If, however, patents only claim specific methods or processes for producing the vaccine, manufacturers may have freedom to operate if they use alternate processes to 'work around' those patents. Patents granted in jurisdictions outside the manufacturing country — especially in potential export markets-might also affect DCVM vaccine development plans. Manufacturers exporting vaccines to these countries would infringe patents if their vaccines embodied the compositions or processes protected by such patents. However, if vaccines had different formulations or were developed by using alternate processes, they could still be sold in the importing country.

We therefore systematically investigated the extent to which patents are a barrier to producing HPV vaccines in LMCs, focusing on India for several reasons. India bears nearly $25 \%$ of the global cervical cancer burden 26,27 and its growing middle class is a potentially large private market for HPV vaccines. Including this vaccine in national immunization programs that target low-income populations will further expand the market, creating strong incentives for local manufacturing of inexpensive alternatives. In addition, several Indian manufacturers who are interested in developing $\mathrm{HPV}$ vaccines have concerns about potential patent impediments to such efforts.

\section{The HPV vaccine patent landscape}

First-generation prophylactic vaccines. Technologies that enabled the development of L1-VLP-based vaccines originated at the US National Institutes of Health's (NIH) National Cancer Institute (NCI), University of Rochester (Rochester, New York, USA), Georgetown University (Washington, DC) and the University of Queensland (Brisbane, Queensland, Australia) (Table 1). MedImmune (Gaithersburg, Maryland, USA), Merck and GSK developed these technologies further and performed safety and efficacy clinical testing to bring the vaccines to mar$\mathrm{ket}^{28}$. The IP landscape for HPV vaccines is complex, with 81 US patents granted so far, linked to 86 specific Patent Cooperation Treaty (PCT) applications. Eighteen entities-ten of which are nonprofit-own these US patents. Nonprofit organizations own 20 of the 81 US patents, for-profits own 55 , and for-profit and nonprofit entities jointly own 6 (Supplementary Table 1). Merck owns the most patents (24), followed by GSK and the US Government (arising from the NCI), who own 8 patents each.

As of December 2008, 19 of the 86 international PCT applications were filed in India
(Table 2). The universities and NIH have not sought patent protection for technologies underlying L1-VLP vaccines in India. However, Merck and GSK have applied for patents on HPV vaccine compositions. GSK alone has filed 13 of these applications. The Indian Intellectual Property Office (IPO) has awarded six patents, four to GSK and one each to Wyeth Holdings (Wayne, New Jersey, USA) and the University of Cape Town (Cape Town, South Africa). Although the determination of patent scope is complicated and sometimes the subject of costly litigation, we offer our preliminary analysis of patent claims based on our understanding of these technologies and discussions with researchers who developed firstgeneration vaccines. Patent 203333, awarded to GSK, claims compositions of a prophylactic vaccine that contains VLPs composed of L1 antigens from HPV-16, 18, 31 and 45. This is detailed in Claim 1, the first independent claim that technically confers the broadest scope of protection and reads, "A vaccine composition comprising virus like particles containing L1 proteins or functional L1 protein derivatives from human papilloma virus 16, human papilloma virus 18 , human papilloma virus 33 and human papilloma virus 45 genotypes wherein the antibody response generated by the vaccine is at a level similar to that for each human papilloma virus, virus like particle formulated alone." Our analysis suggests that only a vaccine containing L1-VLPs from all four HPV strains mentioned in Claim 1 directly infringes the patent. Therefore, Indian manufacturers are probably free to develop a bivalent HPV vaccine containing L1-VLPs for HPV-16 and HPV-18 only or a quadrivalent vaccine containing any combination of three, two or one of these four strains in addition to other unclaimed oncogenic strains. Patent 209780, also awarded to GSK, claims a vaccine composition comprising L1-VLPs for HPV-16, HPV-18 and an adjuvant containing aluminum hydroxide and 3-O-desacyl4'-monophosphoryl lipid A (3dMPL). Claim 1 specifically reads, "A vaccine comprising a human papillomavirus $16 \mathrm{~L} 1$ virus like particles, human papillomavirus $18 \mathrm{~L} 1$ virus like particle, aluminum hydroxide, and 3dMPL." Furthermore, Claim 4 reads, "The vaccine consisting of an HPV 16 L1 VLP, an HPV 18 L1 VLP, aluminum hydroxide, and 3dMPL." However, our analysis suggests that a bivalent (HPV-16, -18 L1-VLP) prophylactic vaccine developed by an Indian manufacturer would not infringe this patent if formulated with a different adjuvant. Additional patents awarded to GSK (Table 2) claim nucleotide sequences of HPV early antigens (214047) and compositions of combination vaccines containing 
HPV L1 antigens (202425) and other antigens, respectively. These too are unlikely to constrain Indian vaccine manufacturers developing Gardasil or Cervarix 'biosimilars'

The University of Cape Town patent claims methods to produce HPV-16 L1-VLPs in tobacco plants and their use in a vaccine composition. However, plant-based expression has so far been unsuccessful in yielding high amounts of purified HPV-16 VLPs ${ }^{11}$, thus limiting the commercial viability of this technology. Patent 220842, awarded to Wyeth, covers polypeptides of HPV early antigens E6 and E7, which are likely to be used in therapeutic cervical cancer vaccine compositions but are less relevant to L1-VLP-based prophylactic vaccines. We found no patents on HPV-16 and HPV-18 L1 nucleic acid sequences filed or awarded in India. However, Merck has four pending patent applications, claiming L1 nucleic acid sequences of HPV subtypes 31, 45, 52 and 58 , optimized for expression in several yeast strains. Because the IPO can choose to significantly narrow the scope of or deny some claims during examination, it is difficult to assess whether Merck's applications will affect vaccine development in India.

Second-generation prophylactic vaccines. Currently, marketed first-generation vaccines are costly to produce as they use expensive expression systems to produce the L1 antigens. Moreover, both miss several oncogenic HPV strains that are present in India and other $\mathrm{LMCs}^{29}$, which is particularly problematic when countries lack the screening programs necessary to detect cancers not prevented by current vaccines. Researchers at the NCI and Johns Hopkins University (Baltimore, Maryland, USA) have developed an L2 (minor capsid antigen)-based vaccine. This approach would protect against infection by all oncogenic strains and would eliminate the costs of increasing the valency of L1-based vaccines ${ }^{11}$.

NCI and Johns Hopkins have partnered with Shantha Biotechnics (Hyderabad, India) to commercialize this candidate. They jointly filed Indian patent application 6219/ DELNP/2007 (Table 2) with the explicit rationale of preserving freedom to operate and market exclusivity for Indian partners (J.T. Schiller \& M. Schmilovich, NCI, NIH; personal communication). Shantha has signed a Cooperative Research and Development Agreement with the NIH, gaining access to biological materials such as codon-optimized plasmids as well as the expertise and training necessary to develop this vaccine. Shantha has nonexclusively licensed this technology from Johns Hopkins ${ }^{30}$. Using an Escherichia coli expression system to purify L2 antigenic peptides, Shantha hopes to lower development costs, thereby making it possible to reduce the price of vaccines significantly 30 (A. Khar \& R. Chaganti, Shantha Biotechnics; personal communication).

Indian patent application 131/CHENP/2007 also bears on second-generation vaccine development and is based on research performed at the University of Lausanne (Lausanne, Switzerland). Denise Nardelli-Haefliger and colleagues showed that recombinant clones of attenuated Salmonella enterica (serovar Typhi and Typhimurium) strains expressing
HPV-16 and HPV-18 L1 antigens can induce a strong immune response $\mathrm{e}^{11,31}$. This technology would allow oral or mucosal immunization against HPV-16 and HPV-18 infection. Lower development and implementation costs associated with this oral vaccine make it highly suitable for use in LMCs. To maximize the potential benefits of this technology to LMCs, Nardelli-Haefliger and colleagues assigned ownership of enabling IP to Indian Immunologicals (Hyderabad) (D. NardelliHaefliger, personal communication). Indian Immunologicals has a memorandum of understanding with Lausanne and has received biological materials, know-how and training. It

\section{Table 1 Timeline of patenting and licensing of HPV L1-VLP-based prophylactic vaccines Date

July 19, 1991 \\ June 25, 1992 \\ September 3, 1992 \\ March 9, 1993 \\ February 1995 \\ October 5, 1995 \\ 1995 \\ June 26, 1996 \\ January 7, 1997 \\ June 24, 1997 \\ December 1997 \\ December 11, 1997 \\ January 16, 1998 \\ October 24, 2001 \\ February 2005 \\ May 2005 \\ September 20, 2005 \\ December 29, 2005 \\ August 20, 2007 \\ Event \\ Frazer et al. (Queensland) file international patent application in Australia Schlegel et al. (Georgetown) file patent application in US \\ Schiller and Lowy et al. ( $\mathrm{NCI}, \mathrm{NIH}$ ) file patent application in US \\ Rose et al. (Rochester) file patent application in US \\ University of Queensland's commercial arm UniQuest licenses HPV vaccine technology to CSL (Melbourne) \\ MedImmune acquires exclusive license to HPV vaccine technology from University of Rochester \\ Merck licenses HPV vaccine technology from CSL \\ Medlmmune in-licenses key HPV IP from German Cancer Research Center \\ $\mathrm{NCI}$ non-exclusively licenses HPV vaccine technology to Medlmmune \\ USPTO declares initial interference \\ $\mathrm{NCI}$ nonexclusively licenses HPV vaccine technology to Merck \\ MedImmune and SmithKline Beecham form worldwide HPV vaccine alliance \\ MedImmune finalizes vaccine agreement with SmithKline Beecham \\ USPTO declares patent interference 104,771 between Rose and Lowy USPTO declares patent interference 104,772 between Rose and Schlegel USPTO declares patent interference 104,773 between Rose and Frazer USPTO declares patent interference 104,774 between Lowy and Schlegel USPTO declares patent interference 104,775 between Lowy and Frazer USPTO declares patent interference 104,776 between Schlegel and Frazer Merck and GSK enter cross-license agreement for HPV patents $\mathrm{NCl}$ 's nonexclusive licenses convert to co-exclusive licenses \\ USPTO Board of Interference announces decision and awards priority to Schlegel et al. \\ Frazer et al. appeal USPTO decision, case docketed in CAFC}

Technologies underlying the L1-VLP based prophylactic vaccines emerged from research conducted at the University of Rochester, the $\mathrm{NCl}$, Georgetown University and the University of Queensland. The $\mathrm{NCl}$ initially nonexclusively licensed the technology to MedImmune and Merck. Medlmmune also acquired worldwide exclusive rights to IP from Georgetown University and the University of Rochester. The University of Queensland licensed its patents to CSL, which in turn licensed the technology exclusively to Merck. GSK eventually acquired exclusive rights to MedImmune's entire IP portfolio for HPV vaccine development. Owing to a first-to-invent system in the United States, patent interference proceedings were triggered at the USPTO when claims overlapped from different patent applications filed by four different groups of inventors. The interference proceedings involved various L1-antigen HPV-related claims. Six two-way patent interferences between the four parties continued for nearly a decade, presumably at significant cost to the institutions or their primary licensees, and were partially resolved in 2005. Given the uncertainty surrounding the ownership of enabling vaccine technologies and the possibility of mutually blocking exclusive rights (that is, neither firm could be sure its products would not infringe on patent rights held by the other), Merck and GSK cross-licensed their respective IP holdings in 2005 to ensure unfettered access to these technologies. They consequently secured their market position in the United States and Europe and other OECD nations such as Canada and Japan. As part of the financial settlement of the patent interference, the nonexclusive licenses awarded by $\mathrm{NCI}$, NIH to MedImmune and Merck were converted to coexclusive licenses, thus allowing both GSK and Merck access to this IP. Merck brought Gardasil to market in the United States in 2006 and Cervarix was introduced in the United Kingdom in June 2008. USPTO, US Patent and Trademark Office; CAFC, US Court of Appeals for the Federal Circuit. 
has also filed international patent applications (Table 2) but will not seek patent protection in Organisation for Economic Co-operation and Development (OECD) markets (R. Sriraman, D. Thiagarajan \& K. Kumar, Indian Immunologicals; personal communication). With assured access to essential patents and know-how, Indian Immunologicals has strong incentives to invest in the development of an oral HPV vaccine. Both the Shantha and Indian Immunologicals vaccines are currently in the preclinical phase. Shantha projects a 2015 market entry at an initial price of $\$ 15$ per dose $\mathrm{d}^{32}$. Both manufacturers believe, however, that prices will drop further as vaccine adoption increases, eventually reaching around \$1-2 per dose, which would make broad access feasible.
Serum Institute of India (Pune) and Bharat Biotech (Hyderabad) are both also developing L1 VLP-based vaccines. Serum's candidate will probably be a bivalent HPV-16 and HPV-18 vaccine. The company will seek a nonexclusive license from the NIH for cell lines optimized for high expression of L1 antigens and will nonexclusively license the Hansenula polymorpha expression platform

\section{Table 2 Patent landscape for HPV vaccines in India}

\begin{tabular}{|c|c|c|c|c|}
\hline $\begin{array}{l}\text { Assignee/ } \\
\text { applicant }\end{array}$ & $\begin{array}{l}\text { PCT application no./ } \\
\text { international } \\
\text { publication no. }\end{array}$ & $\begin{array}{l}\text { Indian application no. } \\
\& \text { application date in } \\
\text { India }\end{array}$ & $\begin{array}{l}\text { Publication date } \\
\text { (application date) }\end{array}$ & $\begin{array}{l}\text { Granted Indian } \\
\text { patent no. } \\
\text { (publication date } \\
\text { of grant) }\end{array}$ \\
\hline $\begin{array}{l}\text { GlaxoSmithKline } \\
\text { Biologicals }\end{array}$ & $\begin{array}{l}\text { PCT/EP2005/006461 } \\
\text { (WO 05/123125) }\end{array}$ & 3436/KOLNP/2006 & $\begin{array}{c}6 / 15 / 2007 \\
(11 / 20 / 2006)\end{array}$ & Pending \\
\hline $\begin{array}{l}\text { GlaxoSmithKline } \\
\text { Biologicals }\end{array}$ & $\begin{array}{l}\text { PCT/EP2003/02826 } \\
\text { (WO 03/077942) }\end{array}$ & 1351/KOLNP/2004 & $\begin{array}{l}12 / 30 / 2005 \\
(9 / 13 / 2004)\end{array}$ & $\begin{array}{c}203333 \\
(4 / 13 / 2007)\end{array}$ \\
\hline
\end{tabular}

$\begin{array}{cllcc}\text { Glaxo Group } & \text { PCT/GB2001/03290 } & \text { 67/MUMNP/2003 } & 2 / 4 / 2005 & 214047 \\ & \text { (WO 02/08435) } & \text { 1561/MUMNP/2007 } & (1 / 16 / 2003) & (1 / 24 / 2008) \\ & & \text { (Divisional of 67/ } & 11 / 9 / 2007 & \text { Pending } \\ & & \text { MUMNP/2003) } & (9 / 27 / 2007) & \end{array}$

GlaxoSmithKline PCT/EP2006/003918 3957/KOLNP/2007 Biologicals (WO 06/114312)

PCT/EP/2000/08784 1471/CHENP/2003

SmithKline Beecham

Biologicals (WO 01/0117551) IN/PCT/2002/336/CHE

$11 / 25 / 2005$

$(9 / 17 / 2003)$ $\mathrm{N} / \mathrm{A}$ $(3 / 5 / 2002)$ PCT/EP2003/01456

Glaxo Group PCT/EP2003/011158 506/KOLNP/2005 (WO 04/031222)

209780

$(9 / 6 / 2007)$

202425

$(4 / 13 / 2007)$

GlaxoSmithKline Biologicals
1336/KOLNP/2003 (WO 02/087614)

(10/16/2003)

Pending
An immunogenic vaccine composition containing VLPs, and/or capsomeres of HPV-16, HPV-18 and at least one other HPV genotype

9/13/2024 An L1-VLP-based vaccine composition containing VLPS of HPV-16, 18, 31 and 45 Vaccine composition further comprising complete or immunologically active fragments of HPV early antigens E1-E8

Vaccine composition further comprising antigens of other STDs including HIV, HSV and Chlamydia

1/16/2023 A synthetic polynucleotide sequence, analog or fragment codon optimized for $E$. coli and encoding the mutated amino acid sequences of HPV early antigen E1, E2 for HPV types/ subtypes selected from HPV strains 1-4, 6 , $7,10,11,16,18,26-29,31,33,35,39$, $49,51,52,56,59,62$ and 68

A p7313Plc backbone-based expression vector capable of driving expression of nucleotide sequences claimed in bacterial cells

L1 proteins of HPV-31, 45 and 52

Method to boost immune response to HPV $16, \mathrm{HPV}-18$ vaccine by using L1 proteins of other HPV subtypes in composition claimed

9/17/2023 A vaccine composition comprising HPV-

3/5/2022 16 L1 VLPS, HPV-18 L1 VLPS, aluminum hydroxide and $3 \mathrm{dMPL}$

A vaccine composition for treating or preventing HPV and HSV infections comprising the HSV gsD2 antigen and an HPV-6, 11,16 or $18 \mathrm{~L} 1$ antigen and an adjuvant that stimulates the $\mathrm{TH} 1$ response

Use of a vaccine composition comprising HPV-16 and HPV-18 VLPs to prevent infection by other oncogenic types of HPV, excluding HPV-16 and HPV-18

Nucleotide sequence of HPV polypeptides: E1 or E2 from oncogenic HPV subtypes Expression vector with codon-optimized polynucleotide sequence

Pharmaceutical composition comprising polynucleotides or vector-encoding nucleotide sequence

A vaccine composition comprising: (i) at least one HIV antigen; and either one or both of (ii) at least one HSV antigen and (iii) at least one (HPV) antigen selected from L1, L2, E6, E7 or a combination thereof 
from Rhein Biotech (Düsseldof, Germany). Serum anticipates a market entry of three to four years after project initiation (S. Singh, Serum Institute; personal communication).

In addition to the L1-VLP vaccine, Bharat scientists are exploring a chimeric L2-HPV vaccine. They plan to express an L2-HBV small surface antigen fusion protein in Picchea pastoris to produce VLPs containing HPV-L2 antigens at high density. Because the HBV surface antigen spontaneously assembles into VLPs, Bharat hopes to reduce the price of the vaccine by circumventing the high costs of purifying and assembling VLPs. Bharat filed a provisional patent application for this vaccine in India last year. Despite developing this technology in-house, Bharat might seek a nonexclusive license from the NIH for the cell lines used in neutralizing assays (S. Kandaswamy, Bharat Biotech; personal communication).

\section{Freedom to operate}

Despite considerable patenting activity, our analysis suggests that IP will not preclude

Table 2 Patent landscape for HPV vaccines in India (continued)

\begin{tabular}{|c|c|c|c|c|c|c|}
\hline $\begin{array}{l}\text { Assignee/ } \\
\text { applicant }\end{array}$ & $\begin{array}{l}\text { PCT application no./ } \\
\text { international } \\
\text { publication no. }\end{array}$ & $\begin{array}{l}\text { Indian application no. } \\
\text { \& application date in } \\
\text { India }\end{array}$ & $\begin{array}{l}\text { Publication date } \\
\text { (application date) }\end{array}$ & $\begin{array}{l}\text { Granted Indian } \\
\text { patent no. } \\
\text { (publication date } \\
\text { of grant) }\end{array}$ & Expiry date & Summary of claims \\
\hline $\begin{array}{l}\text { SmithKline } \\
\text { Beecham } \\
\text { Biologicals }\end{array}$ & $\begin{array}{l}\text { PCT/EP1998/05285 } \\
\text { (WO 99/10375) }\end{array}$ & 1903/MAS/1998 & $\begin{array}{c}3 / 4 / 2005 \\
(8 / 24 / 1998)\end{array}$ & Pending & & $\begin{array}{l}\text { HPV-16 or HPV-18 E6 or E7 HPV pro- } \\
\text { tein in fusion with Hib, lipoprotein D, or } \\
\text { NS I or fragment thereof from influenza } \\
\text { virus, and LYTA or fragment thereof from } \\
\text { Streptococcus pneumoniae }\end{array}$ \\
\hline $\begin{array}{l}\text { SmithKline } \\
\text { Beecham } \\
\text { Biologicals }\end{array}$ & $\begin{array}{l}\text { PCT/EP2000/08728 } \\
\text { (WO 01/17550) }\end{array}$ & IN/PCT2002/335/CHE & $\begin{array}{l}3 / 4 / 2005 \\
(3 / 5 / 2002)\end{array}$ & Pending & & $\begin{array}{l}\text { Multivalent combination vaccine including } \\
\text { HPV (L1, L2, E6, E7) antigens, EBV (gp } \\
350 \text { ), HBV (Sag), hepatitis A (HM-175 } \\
\text { strain), HSV-2 gD VZV antigen (gpl), HCMV } \\
\text { antigen (gB685, pp65), Toxoplasma gondii } \\
\text { antigen (SAG1 or TG34) }\end{array}$ \\
\hline $\begin{array}{l}\text { SmithKline } \\
\text { Beecham } \\
\text { Biologicals }\end{array}$ & $\begin{array}{l}\text { PCT/EP1998/08563 } \\
\text { (WO 99/33868) }\end{array}$ & IN/PCT2000/116/CHE & $\begin{array}{l}3 / 4 / 2005 \\
(6 / 13 / 2000)\end{array}$ & Pending & & $\begin{array}{l}\text { A vaccine composition of HPV E6 or } \\
\text { E7 proteins or fusion of above antigens } \\
\text { with others including Hib, lipoprotein D, } \\
\text { NS I, influenza virus and LYTA of } \\
\text { S. pneumoniae }\end{array}$ \\
\hline \multirow[t]{4}{*}{ Merck \& Co. } & $\begin{array}{l}\text { PCT/EP2004/008677 } \\
\text { (WO 04/084831) }\end{array}$ & 4036/DELNP/2005 & $\begin{array}{l}8 / 31 / 2007 \\
(9 / 8 / 2005)\end{array}$ & Pending & & $\begin{array}{l}\text { Codon-optimized nucleic acid sequence } \\
\text { encoding HPV } 31 \mathrm{~L} 1 \text { and codon-optimized } \\
\text { for expression in yeast strains including } \\
\text { Saccharomyces cerevisiae and Pichia } \\
\text { pastoris }\end{array}$ \\
\hline & & & & & & $\begin{array}{l}\text { Vector and host expressing nucleic acid } \\
\text { claimed }\end{array}$ \\
\hline & & & & & & $\begin{array}{l}\text { VLPs of recombinant HPV- } 31 \mathrm{~L} 1 \text { or L2 pro- } \\
\text { teins or combinations produced in yeast }\end{array}$ \\
\hline & & & & & & $\begin{array}{l}\text { Methods for producing VLPs in yeast using } \\
\text { above nucleotide sequences }\end{array}$ \\
\hline \multirow[t]{3}{*}{ Merck \& Co. } & $\begin{array}{l}\text { PCT/US2005/009199 } \\
\text { (WO 05/097821) }\end{array}$ & 5998/DELNP/2006 & $\begin{array}{c}8 / 24 / 2007 \\
(10 / 16 / 2006)\end{array}$ & Pending & & $\begin{array}{l}\text { Codon-optimized nucleic acid of HPV-52 } \\
\text { L1 for expression in yeast including S. cer- } \\
\text { evisiae and } P \text {. pastoris }\end{array}$ \\
\hline & & & & & & $\begin{array}{l}\text { VLPs of HPV- } 52 \mathrm{~L} 1, \mathrm{~L} 2 \text { or combination } \\
\text { produced in yeast }\end{array}$ \\
\hline & & & & & & $\begin{array}{l}\text { Method of producing HPV-52 L1 or L2 or } \\
\text { combination VLPs in yeast }\end{array}$ \\
\hline \multirow[t]{3}{*}{ Merck \& Co. } & $\begin{array}{l}\text { PCT/US2004/037372 } \\
\text { (WO 05/047315) }\end{array}$ & 2930/DELNP/2006 & $\begin{array}{l}8 / 10 / 2007 \\
(5 / 22 / 2006)\end{array}$ & Pending & & $\begin{array}{l}\text { Codon-optimized nucleic acid of HPV-58 } \\
\text { L1 for expression in yeast ( } S \text {. cerevisiae, } \\
\text { Hansenula polymorpha, P. pastoris, } \\
\text { Kluyveromyces fragilis, Kluyveromyces lac- } \\
\text { tis, Saccharomyces pombe) }\end{array}$ \\
\hline & & & & & & VLPs of HPV-58 L1, L2 or combination \\
\hline & & & & & & $\begin{array}{l}\text { Method of producing HPV-58 L1 or L } 2 \text { or } \\
\text { combination VLPs in yeast }\end{array}$ \\
\hline \multirow[t]{3}{*}{$\begin{array}{l}\text { Indian } \\
\text { Immunologicals }\end{array}$} & $\begin{array}{l}\text { PCT/IB2005/001725 } \\
\text { (WO 05/123762) }\end{array}$ & 131/CHENP/2007 & $\begin{array}{c}8 / 24 / 2007 \\
(1 / 12 / 2007)\end{array}$ & Pending & & $\begin{array}{l}\text { HPV-16 L1 nucleic acid sequence codon- } \\
\text { optimized for expression in prokaryotic } \\
\text { organisms E. coli, Shigella, Lactobacillus, } \\
\text { Mycobacteria, Listeria, or Salmonella- } \\
\text { attenuated strains S. enterica serovar, } \\
\text { S. typhimurium, S. typhi }\end{array}$ \\
\hline & & & & & & $\begin{array}{l}\text { Attenuated strain of microorganism } \\
\text { expressing codon-optimized HPV capsid } \\
\text { protein from HPV-16, 18, 31, } 45\end{array}$ \\
\hline & & & & & & $\begin{array}{l}\text { Method for improving immunogenicity of } \\
\text { a prokaryotic microorganism, specifically } \\
\text { Salmonella against HPV } 16\end{array}$ \\
\hline
\end{tabular}


Table 2 Patent landscape for HPV vaccines in India (continued)

\begin{tabular}{|c|c|c|c|c|c|c|}
\hline $\begin{array}{l}\text { Assignee/ } \\
\text { applicant }\end{array}$ & $\begin{array}{l}\text { PCT application no./ } \\
\text { international } \\
\text { publication no. }\end{array}$ & $\begin{array}{l}\text { Indian application no. } \\
\& \text { application date in } \\
\text { India }\end{array}$ & $\begin{array}{l}\text { Publication date } \\
\text { (application date) }\end{array}$ & $\begin{array}{l}\text { Granted Indian } \\
\text { patent no. } \\
\text { (publication date } \\
\text { of grant) }\end{array}$ & Expiry date & Summary of claims \\
\hline \multirow[t]{2}{*}{$\begin{array}{l}\text { University of } \\
\text { Cape Town, } \\
\text { South Africa }\end{array}$} & \multirow[t]{2}{*}{$\begin{array}{l}\text { PCT/IB2002/03531 } \\
\text { (WO 03/018623) }\end{array}$} & \multirow[t]{2}{*}{ 00831/DELNP/2004 } & \multirow[t]{2}{*}{$\begin{array}{l}4 / 27 / 2007 \\
(3 / 31 / 2004)\end{array}$} & \multirow[t]{2}{*}{$\begin{array}{c}221817 \\
(7 / 7 / 2008)\end{array}$} & \multirow[t]{2}{*}{$3 / 31 / 2024$} & $\begin{array}{l}\text { Modified nucleotide sequences encoding } \\
\text { HPV- } 16 \text { and HPV- } 11 \mathrm{~L} 1 \text { proteins for pro- } \\
\text { ducing VLPs in plant cells where the plant } \\
\text { is Nicotiana benthamiana }\end{array}$ \\
\hline & & & & & & $\begin{array}{l}\text { VLPs produced by this method for use in a } \\
\text { vaccine to treat or prevent HPV infections } \\
\text { in humans }\end{array}$ \\
\hline \multirow[t]{2}{*}{ Wyeth Holdings } & \multirow[t]{2}{*}{$\begin{array}{l}\text { PCT/US2003/031726 } \\
\text { (WO 04/030636) }\end{array}$} & \multirow[t]{2}{*}{ 505/KOLNP/2005 } & \multirow[t]{2}{*}{$\begin{array}{l}2 / 24 / 2006 \\
(3 / 24 / 2005)\end{array}$} & \multirow[t]{2}{*}{$\begin{array}{c}220842 \\
(6 / 6 / 2008)\end{array}$} & \multirow[t]{2}{*}{$3 / 24 / 2025$} & $\begin{array}{l}\text { A fusion polypeptide comprising HPV E6 } \\
\text { and E7 antigen polypeptides where the E6 } \\
\text { antigen has mutations in amino acids } 63 \\
\text { or } 106 \text { and the } E 7 \text { antigen has mutations } \\
\text { in amino acids } 24,26 \text { or } 91\end{array}$ \\
\hline & & & & & & $\begin{array}{l}\text { A nucleotide sequence encoding the above } \\
\text { polypeptide }\end{array}$ \\
\hline Active Biotech & $\begin{array}{l}\text { PCT/SE2000/001808 } \\
\text { (WO 01/023422) }\end{array}$ & $\begin{array}{l}\text { IN/PCT/2002/00438/ } \\
\mathrm{CHE}\end{array}$ & $\begin{array}{c}3 / 4 / 2005 \\
(3 / 21 / 2002)\end{array}$ & Pending & & $\begin{array}{l}\text { A carrier for introducing HPV major capsid } \\
\text { LI protein that has been intentionally } \\
\text { modified to remove major type-specific } \\
\text { epitope(s) that cause production of neu- } \\
\text { tralizing antibodies and which raises a } \\
\text { protective immune response cross-reactive } \\
\text { toward two or more of the group of HPV-LI } \\
\text { proteins comprising LI proteins of HPV-16, } \\
18,31 \text { and } 45\end{array}$ \\
\hline $\begin{array}{l}\text { Government of } \\
\text { the US (NIH); } \\
\text { Johns Hopkins } \\
\text { University }\end{array}$ & $\begin{array}{l}\text { PCT/US2006/003601 } \\
\text { (WO 06/083984) }\end{array}$ & 6219/DELNP/2007 & $\begin{array}{l}8 / 31 / 2007 \\
(8 / 9 / 2007)\end{array}$ & Pending & & $\begin{array}{l}\text { A method for inducing broadly cross- } \\
\text { neutralizing antibodies against cutane- } \\
\text { ous and mucosal HPV types in humans by } \\
\text { administering immunogenic N-terminal } \\
\text { peptides of L2 protein }\end{array}$ \\
\hline
\end{tabular}

The Delphion patent database was searched for HPV vaccine-related patents and patent applications published on or before December 31, 2008, using 'inventor' and 'assignee' names. These results were supplemented with searches of other databases (Derwent Patent Index and the World Intellectual Property Office patent database) to find corresponding international applications filed under the PCT and national phase information. Indian patent filings were identified using two freely available resources, the BigPatents 42 and IPO databases. As neither of the Indian electronic databases included patent claims, we obtained certified hard copies of all granted patents from the four Indian patent offices for claims analysis. For pending Indian applications, we analyzed claims published in corresponding PCT filings. However, there might be pending patent applications not yet published by the IPO that therefore could not be analyzed. We collected information about the licensing status of patents and applications from the US Securities and Exchange Commission filings, and where necessary, directly from patent owners. We identified other legal and/or technological barriers through interviews conducted with HPV vaccine researchers, who developed first- and second-generation vaccines, and technologies relevant to vaccine development in India. We also interviewed researchers and business leaders at four Indian companiesShantha Biotechnics, Indian Immunologicals, Bharat Biotech and Serum Institute of India - that are developing HPV vaccines. STDs, sexually transmitted diseases; HSV, herpes simplex virus; Hib, Haemophilus influenzae type B; EBV, Epstein-Barr virus; HBV (sAg), hepatitis B surface antigen; HCMV, human cytomegalovirus.

manufacturing of first-generation L1-VLPbased vaccines unless they are identical in formulation or strain coverage to those compositions claimed in granted Indian patents. We cannot, however, make this claim definitively owing to uncertainties in interpreting claims and the fate of pending applications. The claims analysis we present is therefore not legal advice but rather a starting point for independent freedom to operate (FTO) analyses by interested parties. Although there are several patents and pending applications on promising second-generation technologies (e.g., L2-based vaccines or oral $\mathrm{L} 1$ vaccines), they so far appear to preserve freedom for DCVMs.

\section{IP transparency}

Recent studies suggest that the lack of IP transparency could be an important impediment for DCVMs exploring new vaccine candidates $^{33}$. Lack of patent claim information in publicly available Indian patent databases made our own research slow and expensive. Our experience mirrored those of Serum (Y. Dalvi, Serum Institute; personal communication) and Bharat. Indeed, Bharat's R\&D was delayed owing to uncertainty about the status of patent protection for HPV antigens in India (S. Kandaswamy, Bharat Biotech; personal communication). Moreover, many countries in Africa, Latin America and Southeast Asia-potential markets for HPV vaccines-lack online patent databases, making it very difficult to determine which LMCs have pending or granted patents. More importantly, LMC companies generally lack the substantial financial and human resources necessary to perform FTO analyses using proprietary databases available in developed countries.

Shantha, Indian Immunologicals and Bharat often rely on researchers to conduct in-house patent searches (R. Chaganti, A. Khar, Shantha; R. Sriraman, D. Thiagarajan, K. Kumar, Indian Immunologicals; S. Kandaswamy, Bharat; personal communication). The WHO
Initiative for Vaccine Research or other agencies could help coordinate FTO and patent landscaping services to advise regional manufacturers on potential IP barriers for HPV vaccine development. The creation of resources to map and update the IP landscape for novel HPV vaccines could facilitate regional manufacturing efforts. This could be developed in partnership with the DCVM network.

\section{Potential roles for universities and funders}

Universities and nonprofit research institutions exploring new HPV vaccines can expedite access to technology in LMCs. The IP management practices of academic institutions, who are the primary generators and gatekeepers of IP for vaccine technologies, will greatly affect regional vaccine manufacturing. The Lausanne-Indian Immunologicals partnership, for example, harnesses the capacity of a DCVM to commercialize a vaccine candidate with potentially high public 
health impact in LMCs despite little commercial interest in OECD countries. The NCI-Johns Hopkins-Shantha partnership to commercialize L2-based vaccine technology further illustrates how IP management can create a pathway for product access in lowincome markets.

University licensing terms are generally not publicly available, except when parties choose to disclose them voluntarily. This has precluded a definitive analysis of whether Rochester, Queensland and Georgetown preserved freedom to use these technologies or subsequent improvements in LMCs when negotiating exclusive licenses with Merck and MedImmune. However, the licensing of vaccine technologies underlying Gardasil and Cervarix does not conform to recent university technology transfer practice guidelines to maximize benefit for the global poor ${ }^{34,35}$. This is understandable because the licenses in question were crafted in the 1980s, before these guidelines were developed. In addition, limited recombinant vaccine production capacity in LMCs rendered humanitarian licensing largely unnecessary at the time. The inaccessibility of HPV vaccines, however, illustrates why recently recommended practice guidelines deserve attention, especially as new technologies for prophylactic or therapeutic vaccines emerge.

Moving forward, universities and other nonprofit research institutions should adopt IP management strategies that preserve options for DCVMs. Preferred practices include default nonexclusive licensing, exclusive licenses with geographic fields of restriction (to ensure LMC companies have FTO), retaining rights to sublicense to regional manufacturers, nonprofit organizations and/or public-private partnerships, humanitarian-use clauses for patented technologies and products, and 'White Knight' clauses to ensure vaccine affordability ${ }^{36,37}$.

Universities can also help to promote IP transparency. Secrecy surrounding licensing exacerbates uncertainties in FTO analyses. Publicly available licensing information can prevent regional manufacturers from wasting time and money on technologies that are blocked by patents and licenses. More importantly, illuminating unblocked pathways can create incentives to commercialize vaccines that are of little interest to OECD manufacturers. Universities owning upstream technologies can promote and compel disclosure of licensing terms as part of licensure to improve transparency. Alternatively, sponsors of university research can make transparency a condition of funding by stipulating (i) disclosure of what geographic regions and fields of use exclusive licenses cover or (ii) publication of licensing contracts. Regional manufacturers can easily identify technologies that are available for licensing and potential partners for vaccine development if a central portal or electronic clearinghouse of all HPV vaccine technologies is created.

\section{Technology transfer: beyond patents}

Although this study focuses on patents, researchers and DCVMs affirm that additional know-how is also crucial for developing new vaccines ${ }^{23}$. Even when technologies are in the public domain or are available for licensing, vaccine development requires considerable expertise ${ }^{38}$. Universities and other non-profit entities can address this need by creating collaborative technology transfer partnerships modeled, for example, on the NIH Rotavirus Technology Transfer program $^{39,40}$. Transfer of three second-generation HPV vaccine technologies to Indian companies potentially increases the likelihood of producing a vaccine better suited for LMCs than current vaccines. Oral, needlefree delivery of HPV vaccines, for example, might reduce the risk of infection of other sexually transmitted agents such as HIV and HSV, eliminate multiple healthcare visits, and increase patient compliance in resource-poor regions if doses can be administered at home as reconstituted oral drops. Collaborative partnerships with DCVMs might also produce vaccines designed from the onset to meet specific implementation characteristics of resource-poor regions, such as heat-stable formulations and single-dose or combination vaccines. Finally, market competition between one or more second-generation vaccines will probably reduce prices.

\section{Conclusions}

Experiences with introducing new vaccines suggest that 20 years could pass before women in LMCs gain access to HPV vaccines $^{41}$. Meanwhile, every five-year delay in vaccine introduction could result in nearly 1.5 to 2 million more HPV-related deaths ${ }^{1}$. The prevention of these fatalities will require vaccines that entail fewer doses, minimize interactions with healthcare professionals, and are suitable for delivery in a resourcepoor setting. Although these are tremendous challenges independent of price, improved access to HPV vaccines will depend on a reduction in vaccine prices. Regional manufacturers can accomplish this by lowering production costs and by developing vaccines tailored for resource-poor settings. Furthermore, increased DCVM competition can lower prices. Our patent landscape suggests that patents on first-generation vaccines do not seriously inhibit the development efforts of DCVMs. Regional manufacturers, national governments and international agencies should consider this an opportunity and take the necessary steps to make low-cost vaccine production a possibility.

Academic research institutions, from which most HPV vaccine technologies emerged, can play an important role in supporting regional manufacturing. Their technology transfer practices can promote new channels for regional manufacturing while ensuring that licensing does not block pathways to low-cost regional manufacturing of existing vaccines. Improving access to know-how and creating IP transparency can further facilitate regional manufacturing. By participating in technology transfer partnerships and adopting favorable IP management practices, universities can expedite access to new generations of life-saving HPV vaccines and increase the public health impact of these vaccines in LMCs.

Note: Supplementary information is available on the Nature Biotechnology website.

\section{ACKNOWLEDGMENTS}

We thank all the interviewees for their voluntary participation in this study, and J.T. Schiller and $\mathrm{M}$. Angrist for helpful discussion and comments. S.P. was supported by travel awards from the Alice M. Baldwin Scholars program at Duke University, the Janet B. Chiang grant from the Asian and Pacific Studies Institute at Duke University, the Dannenberg Awards, the Stay In Focus grant from the Focus Program and the Public Policy Studies Department at Duke University. S.C. and R.C.-D. gratefully acknowledge the support of the National Human Genome Research Institute and the Department of Energy (CEER grant P50 HG003391, Duke University, Center of Excellence for ELSI Research). S.C. and R.C.-D. also received a grant from the Charles M. Josiah Trent Foundation that supported travel for S.C. T.A. gratefully acknowledges the support of the Echoing Green Fellowship.

\section{COMPETING FINANCIAL INTERESTS}

The authors declare no competing financial interests.

1. Agosti, J.M. et al. N. Engl. J. Med. 356, 1908-1910 (2007).

2. Gakidou, E. et al. PLoS Med. 5, e132 (2008).

3. Lowy, D.R. et al. J. Clin. Invest. 116, 1167-1173 (2006).

4. CDC Vaccine Price List. <http://www.cdc.gov/vaccines/ programs/vfc/cdc-vac-price-list.htm> (accessed 20 January 2010).

5. Anonymous. Making cervical cancer vaccines widely available in developing countries: cost and financing issues. (International AIDS Vaccine Initiative, New York and PATH, Seattle, March 2008; accessed 20 January 2010). <http://screening.iarc.fr/doc/IAVI_PATH_HPV_ financing brief.pdf $>$

6. Anonymous. HPV vaccine adoption in developing countries: cost and financing issues. (International AIDS Vaccine Initiative, New York and PATH, Seattle, March 2008; accessed 20 January 2010). <http://www.rho.org/ files/IAVI_PATH_HPV_financing.pdf $>$

7. Kaiser, J. Science 320, 860 (2009).

8. Anonymous. India's first vaccine for cervical cancer launched. Thaindian News 20 October $2008<$ http:// 


\section{PATENTS}

www.thaindian.com/newsportal/health/indias-first-vaccine-for-cervical-cancer-launched_100109462.html> (accessed 20 January 2010).

9. Goldie, S.J. et al. Reprod. Health Matters 16, 86-96 (2008).

10. Diaz, M. et al. Br. J. Cancer 99, 230-238 (2008).

11. Schiller, J.T. et al. Vaccine 24, 147-153 (2006).

12. Anonymous. Donating more than one million vaccines to help Nicaraguan babies. (Merck, Whitehouse Station, New Jersey, 2009, 2010; accessed 20 January 2010)_<http://www.merck.com/responsibility/access/access-feature-nicaraguan.html>

13. Anonymous. GSK Rotavirus vaccine donation to Good Shepherd Social Welfare Services Babies Home (Good Shepherd Sisters Taiwan, 14 December 2006 accessed 20 January 2010) <http://www.goodshepherd.org.tw/eng/index.php?option=com_content\&tas k=view\&id=64\&ltemid $=54>$

14. Tsu, V. PATH/Seattle, personal communication (2011)

15. Anonymous. Gardasil Access Program. <http://gardasilaccess-program.org/index.php> (accessed 20 January 2010).

16. Batson, A. et al. Vaccine 24, 219-225 (2006).

17. Ghandi, G. Update on GAVI Alliance: renewed strategic vision and governance. (UNICEF, Copenhagen, 10-11 December 2008; accessed 20 January 2010) <http:/ www.unicef.org/supply/files/3_-_GAVI_Vaccine_Pretender_Meeting(10Dec08)_GGandhi_v3.pdf>

18. Anonymous. All girls deserve protection from cer- vical cancer. (GAVI Alliance, Geneva, 4 February 2009; accessed 20 January 2010) <http://www. gavialliance.org/media_centre/press_releases/HPV World_Cancer_Day.php>

19. Lydon, P. et al. Vaccine 26, 6706-6716 (2008).

20. Jodar, L. \& Clemens, J.D. in The Grand Challenge for the Future Vaccines for Poverty-Related Diseases from Bench to Field (eds. Kaufmann, S.H.E. \& Lambert, P.H.) 55-73 (Birkhäuser, Basel, 2005).

21. Anonymous. GAVI Alliance Progress Report (GAVI Alliance, Geneva, 2007; accessed 20 January 2010) <http://www.gavialliance.org/ resources/2007GAVIreport.pdf>

22. Anonymous. Global progress toward universal childhood hepatitis B vaccination. MMWR Weekly, 12 September 2003 <http://www.cdc.gov/mmwr/preview/mmwrhtml/ mm5236a5.htm> (accessed 20 January 2010).

23. Milstien, J.B. et al. Health Aff. 25, 1061-1069 (2006).

24. Maybarduk, P. \& Rimmington, S. Am J. Law Med. 35, 323-350 (2009).

25. Outterson, K. et al. Health Aff. 27, 130-139 (2008).

26. Sankaranarayanan, $R$, et al. Vaccine 26, M43-M52 (2008).

27. Ferlay, J. et al. GLOBOCAN2002: Cancer incidence, mortality and prevalence worldwide. IARC Cancer Base No. 5 Version 2.0. (IARC Press, Lyon, France, 2004). 28. Inglis, S. et al. Vaccine 24, 99-105 (2006).

29. Sankaranarayanan, R. et al. Vaccine 26S, M43-M52
(2008).

30. Jagu, S. et al. J. Natl. Cancer Inst. 101, 782-792 (2009)

31. Fraillery, D. et al. Clin. Vaccine Immunol. 14, 1285 1295 (2007)

32. Sinha, G.P. Shantha developing $\$ 15$ cervical cancer vaccine. The Economic Times 16 Oct 2007 <http:// economictimes.indiatimes.com/News/News_By_ Industry/Shantha_developing_15_cervical_cancer vaccine/articleshow/2461640.cms> (accessed 20 January 2010).

33. Milstien, J.B. et al. Vaccine 25, 7610-7619 (2007)

34. Chokshi, D.A. et al. J. Am. Med. Assoc. 298, 1934 1936 (2007)

35. Chaifetz, S. et al. Global. Health 3, 1 (2007).

36. Mahoney, R.T. et al. Vaccine 22, 786-792 (2004).

37. Salicrup, L.A. et al. Biotechnol. Adv. 24, 69-79 (2006).

38. Batson, A. Health Aff. 27, 140-142 (2008).

39. MIHR/PIPRA. IP Handbook of Best Practices Rotavirus Vaccine: NIH Office of Technology Transfer case study. <http://www.iphandbook.org/handbook/ case_studies/cs13/ $\geq$ (accessed 20 January 2010).

40. Salicrup, L.A. Nat. Biotechnol. 25, 976-977 (2007).

41. Kane, M.A. et al. Vaccine 24, 132-139 (2006).

42. BigPatents India. <http://india.bigpatents.org/> (accessed 20 January 2010).

Corrected online 8 February 2012. 


\section{Erratum: Factors influencing agbiotech adoption and development in sub-Saharan Africa}

Obidimma C Ezezika, Abdallah S Daar, Kathryn Barber, Justin Mabeya, Fiona Thomas, Jennifer Deadman, Debbie Wang \& Peter A Singer Nat. Biotechnol. 30, 38-40 (2012); published online 9 January 2012

In the version of this article published in print, the affiliations were omitted. The error was corrected before online publication in the HTML and PDF versions of the article.

\section{Erratum: Amelioration of sepsis by inhibiting sialidase-mediated disruption of the CD24-SiglecG interaction}

Guo-Yun Chen, Xi Chen, Samantha King, Karen A Cavassani, Jiansong Cheng, Xincheng Zheng, Hongzhi Cao, Hai Yu, Jingyao Qu, Dexing Fang, Wei Wu, Xue-Feng Bai, Jin-Qing Liu, Shireen A Woodiga, Chong Chen, Lei Sun, Cory M Hogaboam, Steven L Kunkel, Pan Zheng \& Yang Liu

Nat. Biotechnol. 29, 428-435 (2011); published online 6 May 2011; corrected after print 18 January 2012

In the version of this article initially published, a line in the abstract read, "repressed by the t interaction...." It should have read, "repressed by the interaction..." The error has been corrected in the HTML and PDF versions of the article.

\section{Corrigendum: Industry continues dabbling with open innovation models}

Cormac Sheridan

Nat. Biotechnol. 29, 1063-1065 (2011); published online 8 December 2011; corrected after print 8 February 2012

In the version of this article initially published, Richard Anderson is named incorrectly and so is his affiliation as director of the Initiative for Open Innovation. The source's correct name is Richard Jefferson and he is founder and CEO of Cambia, a not-for-profit biotech research institute based at the Queensland University of Technology, in Brisbane, Australia. The error has been corrected in the HTML and PDF versions of the article.

Corrigendum: FDA panel votes to pull Avastin in breast cancer, again

Mark Ratner

Nat. Biotechnol. 29, 676 (2011); published online 5 August 2011; corrected after print 8 February 2012

In the version of this article initially published, only “ovarian and small cell lung cancer” were said to be among Avastin's current FDA-approved uses. In the US, Avastin is currently approved for advanced colon, non-small cell lung, glioblastoma and kidney cancers. FDA withdrew Avastin's breast cancer approval in November 2011 (Nat. Biotechnol. 30, 6 (2012). The error has been corrected in the HTML and PDF versions of the article.

\section{Corrigendum: Chinese vaccine developers gain WHO imprimatur}

Hepeng Jia \& Karen Carey

Nat. Biotechnol. 29, 471-472 (2011); published online 7 June 2011; corrected after print 8 February 2012

In the version of this article originally published, in Table 1, Sinovac Biotech was described as having been acquired by Novartis in March. Novartis acquired a different company, Tianyuan, as stated later in the article.

\section{Corrigendum: Intellectual property, technology transfer and manufacture of low-cost HPV vaccines in India}

Swathi Padmanabhan, Tahir Amin, Bhaven Sampat, Robert Cook-Deegan \& Subhashini Chandrasekharan

Nat. Biotechnol. 28, 671-678 (2010); published online 8 July 2010; corrected after print 8 February 2012

In the version of this article initially published, on p. 671, column 2, the authors state: "Merck has donated three million doses of Gardasil to the Program for Appropriate Technology in Health (PATH) for demonstration trials ${ }^{14}$. Its Gardasil Access Program aims to extend this support to eight LMCs ${ }^{15}$ " It should have read: "Merck donated about 130,000 doses to PATH for demonstration studies in India, Peru and Vietnam ${ }^{14}$. Through the Gardasil Access Program, Merck aims to extend its support to LMCs and has pledged to make 3 million doses of vaccine available to eligible countries ${ }^{15}$ ". In addition, reference 14 should have been Tsu, V. PATH/Seattle, personal communication (2011), rather than Harner-Jay et al. J. Pharm. Sci. (2008). 